\title{
The effects of the primary health care providers' prescription behavior interventions to improve the rational use of antibiotics: a systematic review
}

Lu Yao ${ }^{1,2,3}$, Jia Yin ${ }^{1,2}$, Ruiting Huo ${ }^{1,2}$, Ding Yang ${ }^{1,2}$, Liyan Shen ${ }^{1,2}$, Shuqin Wen ${ }^{1,2}$ and Qiang Sun ${ }^{1,2^{*}}$

\begin{abstract}
Background: Irrational antibiotics use in clinical prescription, especially in primary health care (PHC) is accelerating the spread of antibiotics resistance (ABR) around the world. It may be greatly useful to improve the rational use of antibiotics by effectively intervening providers' prescription behaviors in PHC. This study aimed to systematically review the interventions targeted to providers' prescription behaviors in PHC and its' effects on improving the rational use of antibiotics.
\end{abstract}

Methods: The literatures were searched in Ovid Medline, Web of Science, PubMed, Cochrane Library, and two Chinese databases with a time limit from January 1st, 1998 to December 1st, 2018. The articles included in our review were randomized control trial, controlled before-and-after studies and interrupted time series, and the main outcomes measured in these articles were providers' prescription behaviors. The Cochrane Collaboration criteria were used to assess the risk of bias of the studies by two reviewers. Narrative analysis was performed to analyze the effect size of interventions.

Results: A total of 4422 studies were identified in this study and 17 of them were included in the review. Among 17 included studies, 13 studies were conducted in the Europe or in the United States, and the rest were conducted in low-income and-middle-income countries (LMICs). According to the Cochrane Collaboration criteria, 12 studies had high risk of bias and 5 studies had medium risk of bias. There was moderate-strength evidence that interventions targeted to improve the providers' prescription behaviors in PHC decreased the antibiotics prescribing and improved the rational use of antibiotics.

Conclusions: Interventions targeted PHC providers' prescription behaviours could be an effective way to decrease the use of antibiotics in PHC and to promote the rational use of antibiotics. However, we cannot compare the effects between different interventions because of heterogeneity of interventions and outcome measures.

\footnotetext{
* Correspondence: qiangs@sdu.edu.cn

${ }^{1}$ Centre for Health Management and Policy Research, School of Public

Health, Cheeloo College of Medicine, Shandong University, Jinan 250012,

China

${ }^{2} \mathrm{NHC}$ Key Lab of Health Economics and Policy Research (Shandong

University), Jinan 250012, China

Full list of author information is available at the end of the article
}

(c) The Author(s). 2020 Open Access This article is licensed under a Creative Commons Attribution 4.0 International License, which permits use, sharing, adaptation, distribution and reproduction in any medium or format, as long as you give appropriate credit to the original author(s) and the source, provide a link to the Creative Commons licence, and indicate if changes were made. The images or other third party material in this article are included in the article's Creative Commons licence, unless indicated otherwise in a credit line to the material. If material is not included in the article's Creative Commons licence and your intended use is not permitted by statutory regulation or exceeds the permitted use, you will need to obtain permission directly from the copyright holder. To view a copy of this licence, visit http://creativecommons.org/licenses/by/4.0/. 


\section{Background}

Antibiotics resistance (ABR) is a growing public health problem [1], which delayed the therapy effectiveness, greatly increasing the health costs and the risk of morbidity and mortality [2]. In 1998, the World Health Assembly initially issued a separate motion on ABR and put forward a comprehensive management proposal to respond to the emergence of $A B R$ [3]. In the same year, the World Health Organization (WHO) advocated to cope with the ABR crisis by promoting the rational use of antibiotics globally [4].

The healthcare providers' prescribing behaviours is an important area to promote the rational use of antibiotics. The previous studies have shown that many countries have been successful in reducing prescribing of antimicrobials in secondary and tertiary hospitals in the past decades. However, irrational use of antibiotics in primary health care (PHC) was still problematic, and especially in the context when a large majority of people are prescribed with antibiotics [5, 6]. It is estimated that about $80 \%$ antimicrobials were consumed in PHC around the world [7]. Therefore, effetive interventions to improve healthcare providers' prescribing behaviours in PHC would greatly improve the rational use of antibiotics.

A Cochrane review in 2017 examined the effectiveness of interventions on health professionals' antibiotics prescribing practices for hospital inpatients, and it was observed that antimicrobial stewardship interventions can greatly reduce unnecessary antibiotics use in hospital settings [8]. These interventions are typically classified as educational intervention, audit and feedback interventions, health policy change strategies, as well as organizational or professional financial incentives to improve the quality of antibiotics prescribing [8]. Several reviews has also reported positive effects of hospital antibiotics stewardship interventions. And there are types of interventions, structure interventions such as new technology for rapid microbiology testing or measurement of inflammatory markers, persuasive interventions like expert audit of prescriptions and feedback advice to prescribers, enabling interventions like guidelines or education on antibiotics use and restrictive interventions like expert approval for use of certain antibiotics) $[9,10]$.

Preliminary analysis suggests that very few studies are conducted to explore the effectiveness of interventions to decrease antibiotics prescribing and to promote the antibiotics prescribing behaviours from the perspective of primary health providers. This also necessities to have a thorough analysis of the issue. In this context the current systematic review is planned. The objective of the review is to conduct a systematic review of literature to evaluate the effects of the primary health care providers' prescription behavior interventions in improving the rational use of antibiotics.

\section{Methods}

The review protocol of this study, with the search strategy included, was registered at the PROSPERO international prospective register of systematic reviews (CRD: 42019146631).

\section{Search strategy}

We searched the following databases from January 1st, 1998 to December 1st, 2018: The databases include Ovid Medline, Web of Science, PubMed and Cochrane Library were searched for relevant studies published in English, and the databases of China National Knowledge Infrastructure (CNKI) and WANFANG database were searched for Chinese language studies. The Chinese databases were searched using the following terms (in Chinese): 'prescription', 'community', 'primary health', 'outpatient', 'rural doctors', 'village doctors' 'intervention', 'antimicrobial', 'antibacterial' and 'antibiotics'. The search strategies used to search at Ovid Medline, Web of Science, PubMed and Cochrane Library can be seen in the Supplemental documents. Identification of relevant studies was carried out by one researcher and checked by two other researchers. Additional studies were identified by cross-referencing. The experts were also consulted for additional literature. The flow chart of the searching was referred to the PRISMA protocol.

\section{Inclusion and exclusion criteria}

We included studies according to PICOS (population, intervention, comparison, outcome and study design) characteristic. Population: the participants refer to the physicians at outpatient clinics, general practitioners, rural doctors; the patients included were not specified (e.g. respiratory tract infections or urinary tract infections). Intervention: the studies regarding promoting the antibiotics rational use and the interventions targeted towards primary health care providers. We referred EPOC (Cochrane Effective Practice and Organisation of Care) taxonomy (EPOC 2015) [11] to include interventions of educational, audit and feedback, reminders and health policies changes. Outcomes: the primary outcome were the changes in antibiotics prescribing behaviors of providers, including the changes in antibiotics prescribing rates, the odds ratio of antibiotics prescribing, the percentage of prescriptions of specific antibiotics or prescribing appropriateness. Study design: the design of the studies had to be RCTs (randomized controlled trials), ITS (interrupted times series) or controlled before-and-after studies.

Articles were excluded if they focused on microbiology; were non-research articles such as reviews, meeting reports, policy briefs; or did not focus on outpatient antibiotics prescriptions. Titles and abstracts were independently screened for eligibility by two authors. In order to maintain agreement, the two researchers evaluated the quality of studies by reading the full-text articles. 


\section{Data extraction and analysis}

We used the data extracted forms from the Cochrane Handbook for Systematic Reviews [12]. The following information was extracted from each included article: first author and year of publication, study design, setting, country, participants, intervention details, target illness, duration and outcomes measures. Narrative synthesis was used due to the great heterogeneity among the included studies.

\section{Quality assessment}

We assessed the risk of bias based on the Cochrane Collaboration criteria (Higgins 2011) [12]. We used eight standard criteria for RCTs: random sequence generation, allocation concealment, blinding of participants, blinding of outcome assessment, incomplete outcome data, selective reporting and no risk of bias from other sources. We used two additional criteria that the EPOC (Cochrane Effective Practice and Organization of Care) Group specifies (EPOC 2009): baseline characteristic similarity, as well as "adequate protection against contamination".

We used seven criteria for NRT (non-randomized trial): the intervention is independent of other changes, the shape of the intervention effect is pre-specified, the intervention is unlikely to affect data collection, knowledge of the allocated interventions is adequately prevented during the study, the outcome data are incomplete, selective reporting, and other bias.

The Cochrane Collaboration criteria was used to assessed the risk of bias of the studies by two reviewers.
The disagreements between reviewers' judgements were resolved by discussion and consensus.

\section{Results}

The process of study identification and inclusion is shown in Fig. 1. A total of 4422 articles were identified as relevant. After reviewing the abstracts and full texts, 17 studies were included, of which, 16 were in English and 1 was in Chinese.

\section{Study characteristics Population}

Of the 17 studies, ten were conducted in Europe [13, $15-18,20,21,25,26,28]$, four in China [14, 22-24], three in the USA $[19,27,29]$. Table 1 provides a summary of the key characteristics of each included study. All interventions were targeted at primary health care providers including general practitioners and primary health care physicians, but excluding specialist care or outpatient department in a hospital setting. These studies focus on patients who were diagnosed with respiratory tract infections, urinary tract infections, upper respiratory tract infections.

\section{Intervention}

Diverse interventions were observed in the included studies, five of which mainly evaluated the educational interventions, i.e., educational material, guidelines, training sessions; four used audit and feedback interventions

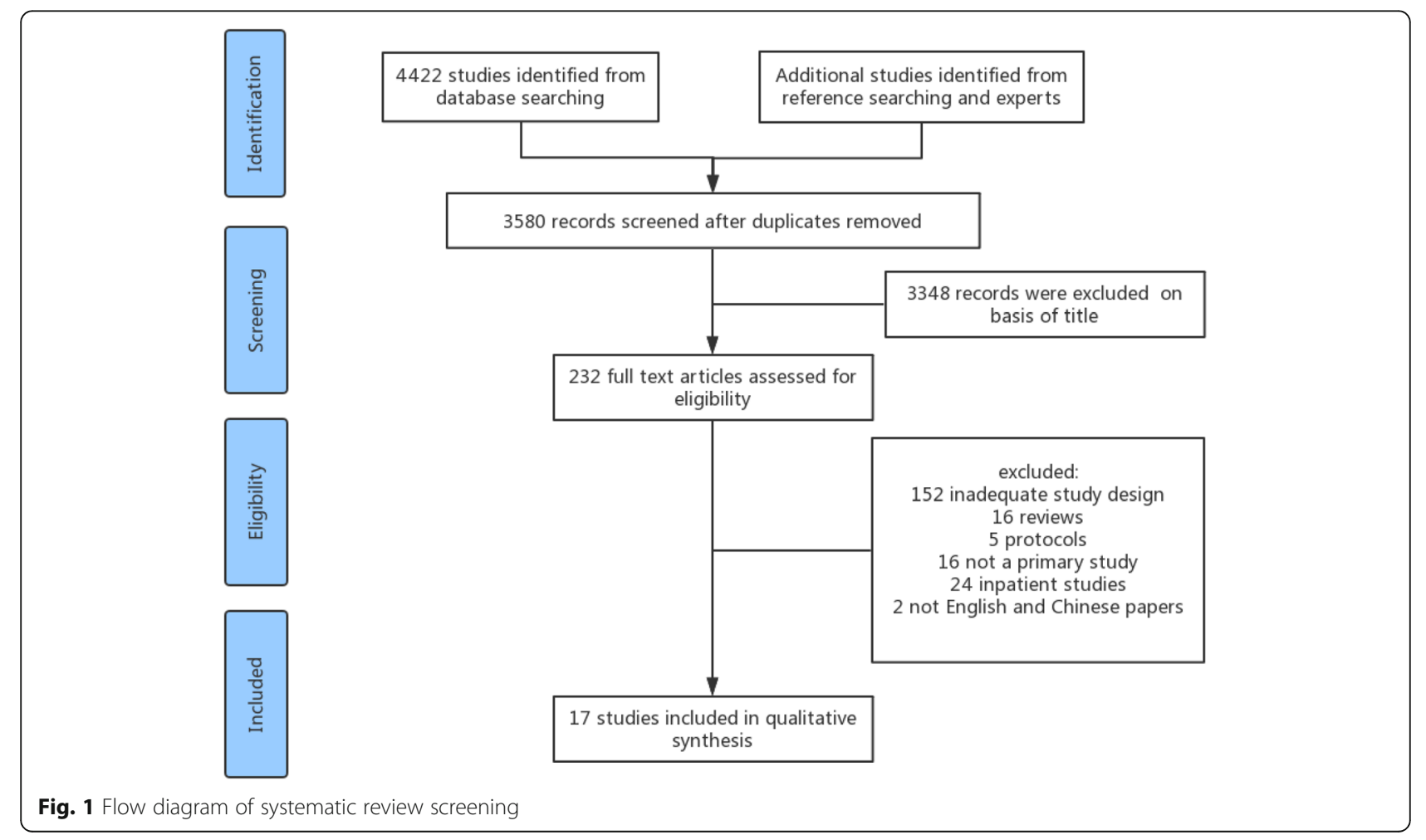




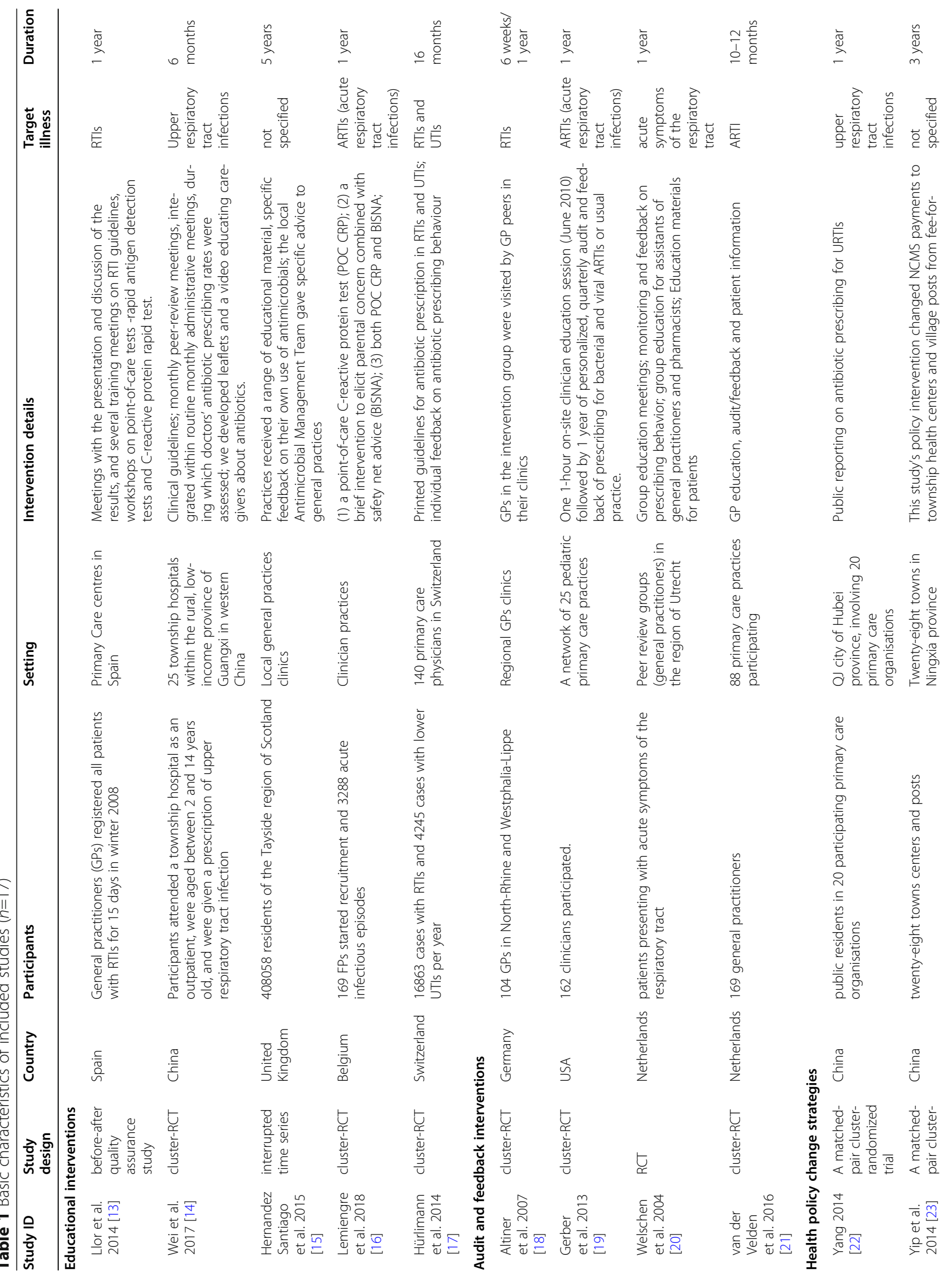




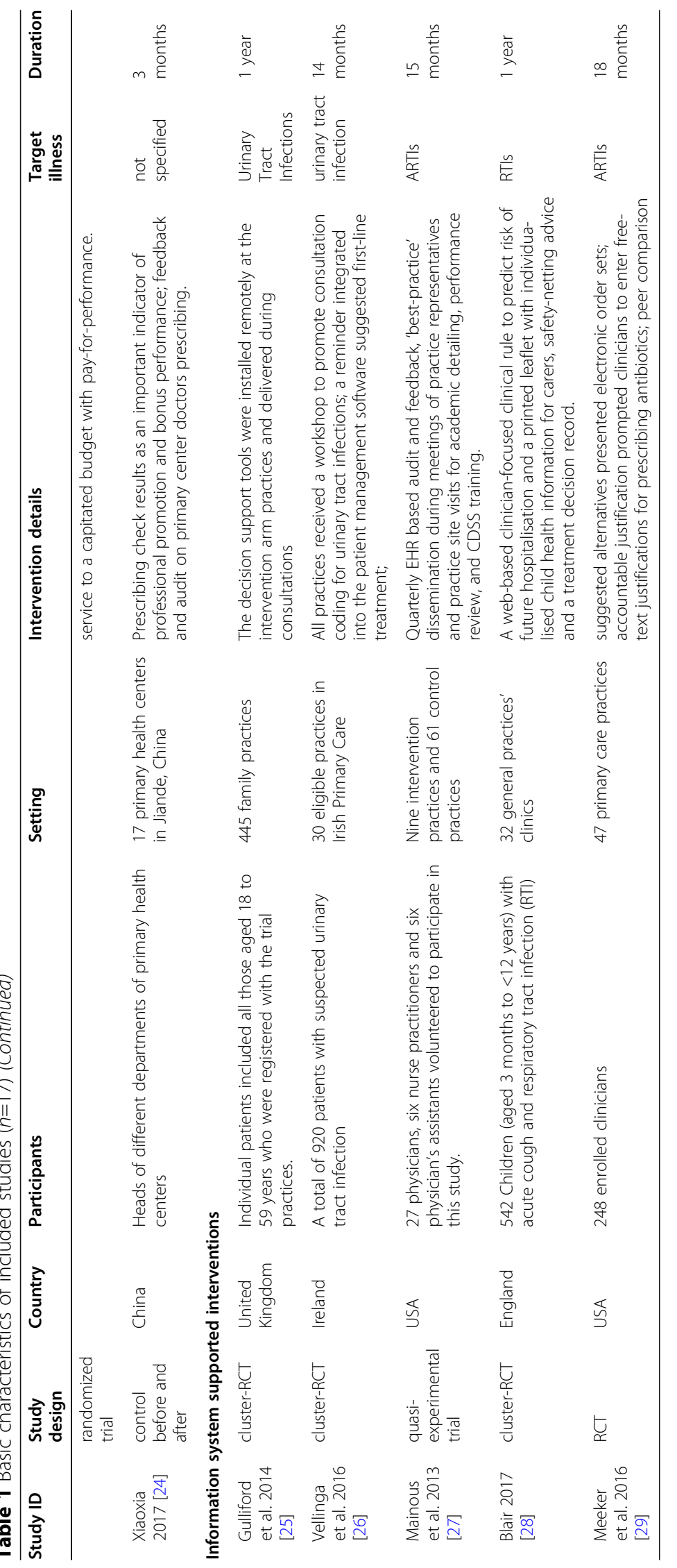


including peer review about the prescribing, monitoring and feedback on prescribing behaviors; three used health policy change strategies including public report prescriptions, changing in payments methods and including the antibiotics using into performance. The other five employed health information system supported interventions. These were related to clinical supported decisionmaking system and also related to providing online guideline materials.

\section{Outcomes measured}

The most frequently measured outcome was antibiotics prescribing rate. Thirteen studies measured a change in antibiotics prescription rate or the odds ratio of antibiotics prescribing $[13,14,16,18-23,25-29]$. The antibiotics prescription rate defined as the proportion of prescriptions for specific disease that include at least one antibiotic. One study measured the impact of interventions on the rate per 1000 registered patients dispensed one or more $4 \mathrm{C}$ antimicrobial prescriptions (co-amoxiclav, cephalosporins, fluoroquinolones and clindamycin) [15]. Another study measured the effect on prescriptions of penicillin for RTIs (respiratory tract infections) and one on proportion of prescriptions for recommended [17]. One Chinese study measured the effect on changes in types of antibioticss [24]. Akke Vellinga used the proportion of antimicrobial prescribing of guidelines for urinary tract infection to measure the changes of providers prescription behaviors [26].

\section{Study design}

There were nine cluster random control trials [14, 16$19,21,25,26,28]$, two matched-pair cluster-randomized trials [22, 23], two RCTs [20, 29], two before and after intervention studies [13, 24], one quasi-experimental trial [27] and one interrupted time series study [15].

\section{Risk of bias assessment}

The risk of bias was considered low if all criteria were scored as low, medium if less than three criteria were scored as medium or high, and high if more than three criteria were scored as medium or high [30]. For $13 \mathrm{RCTs}$, the risk of bias was medium for four studies $[16,18,23,26]$ and high for nine studies [14, 17, 19-22, 25, 28, 29]. The main risk of the studies was that we did not know how the random sequence generated, and the blinding of participants and personnel. For the four NRTs, the risk of the bias was medium in one study [15], high for three studies [13, 24, 27]. And the main risk was the interventions were not independent of other changes. (Figs. 2 and 3).

\section{Effect of interventions}

Our research found that 11 of the 17 studies reported reductions of antibiotics prescribing rate between the two arms with the largest effect size reaching $29 \%$ of antibiotics prescribing. This was for upper respiratory tract infections (URTIs) in children. Three studies found improvement in in providers' prescribing behaviours according to their guidelines. The other three studies did not find a significant difference in the prescribing rate between the intervention and the control group. Only three studies reported the sustainable effect of the interventions.

The findings of all included studies measuring the changes in antibiotics prescribing are summarized in Table 2.

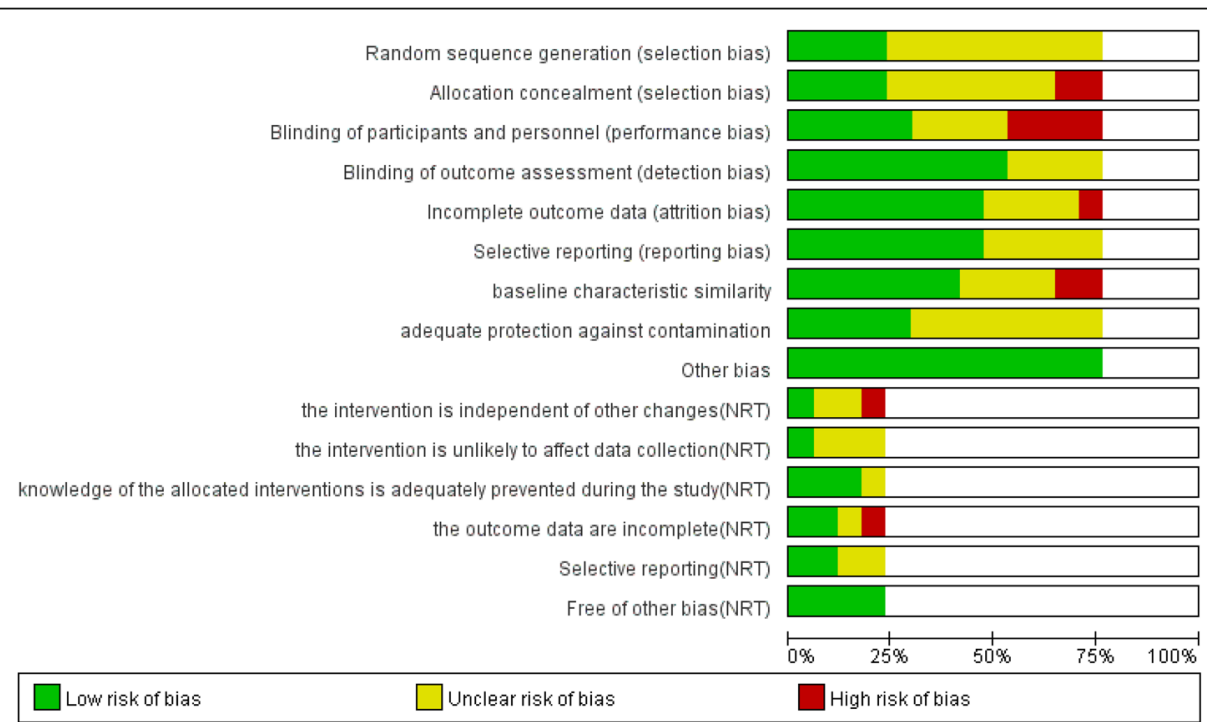

Fig. 2 Risk of bias graph: review authors' judgements about each risk of bias item presented as percentages across all included studies. Blank sections in this graph are due to use of different ROB criteria for RCT versus ITS studies 


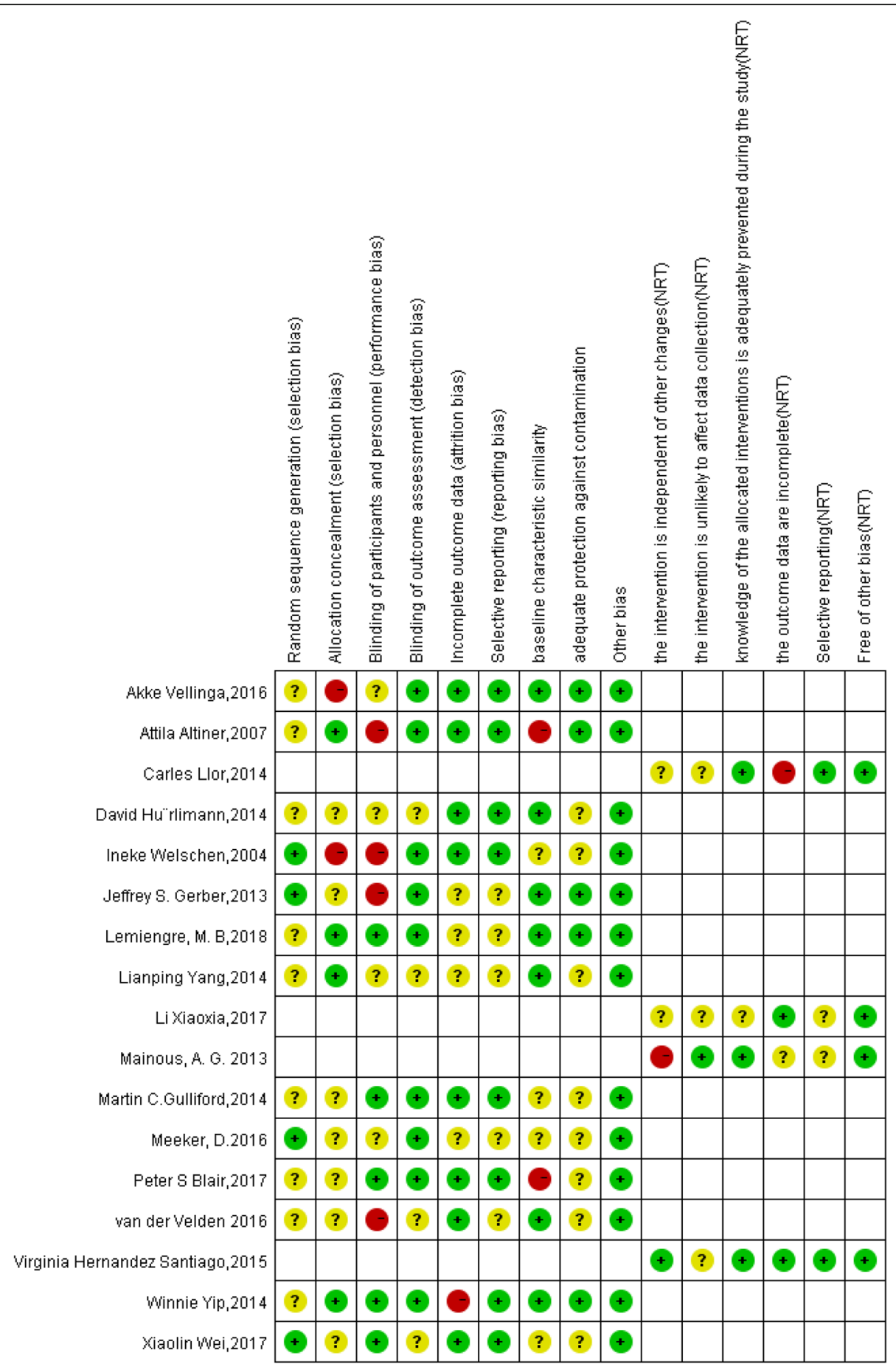

Fig. 3 Risk of bias summary: the yellow circles mean the unclear risk of bias or the author did not mention the bias, the green circles mean the low risk of bias, the red circles mean the high risk of bias

\section{Educational interventions}

Five studies used education interventions and out of these 5 studies? four studies reported improvements in providers' behaviours of antimicrobial prescribing. Most educational interventions were multifaceted and included clinical guidelines, distribution of educational materials to prescribers to support clinical care, courses, workshops, conferences or other educational meetings. The greatest improvement was one ITS study reported by Virginia Hernandez who evaluated the use of educational material in British general practices regarding the of antimicrobials [15]. It was observed that after 6,12 and 24 months, there 
Table 2 Antibiotic prescribing changes among these included studies

\begin{tabular}{|c|c|c|c|c|c|}
\hline First author, year & Primary outcome(s) & $\begin{array}{l}\text { Change in } \\
\text { intervention } \\
\text { group }\end{array}$ & $\begin{array}{l}\text { Change in } \\
\text { control } \\
\text { group }\end{array}$ & $\begin{array}{l}\text { Effect size } \\
(95 \% \mathrm{Cl})\end{array}$ & $\begin{array}{l}P \\
\text { value }\end{array}$ \\
\hline \multicolumn{6}{|c|}{ Educational interventions } \\
\hline \multirow[t]{2}{*}{$\begin{array}{l}\text { Llor et al. } 2014 \\
\text { [13] }\end{array}$} & $\begin{array}{l}\text { change in the odds ratio of antibiotic prescribing (full intervention } \\
\text { group) }\end{array}$ & & & $\begin{array}{l}0.50(0.44 \text { to } \\
0.57,)\end{array}$ & $\begin{array}{l}p< \\
0.001\end{array}$ \\
\hline & $\begin{array}{l}\text { change in the odds ratio of antibiotic prescribing (partial } \\
\text { intervention group) }\end{array}$ & & & $\begin{array}{l}0.99(0.89 \text { to } \\
1.10)\end{array}$ & NR \\
\hline \multirow[t]{4}{*}{$\begin{array}{l}\text { Wei et al. } 2017 \\
{[14]}\end{array}$} & Antibiotic prescription rate & $-42 \%$ & $-5 \%$ & $-29 \%$ & $\begin{array}{l}< \\
0.001\end{array}$ \\
\hline & the multiple antibiotic prescription rate & $-6 \%$ & $6 \%$ & $1 \%$ & 0.57 \\
\hline & the broad-spectrum antibiotic prescription rate & $-10 \%$ & $-5 \%$ & $-4 \%$ & 0.3 \\
\hline & the intravenous antibiotic prescription rate & $-6 \%$ & 0 & $-8 \%$ & 0.07 \\
\hline \multirow[t]{3}{*}{$\begin{array}{l}\text { Hernandez } \\
\text { Santiago et al. } \\
2015[15]\end{array}$} & $\begin{array}{l}\text { the rate per } 1000 \text { registered patients dispensed one or more } 4 C \\
\text { antimicrobial prescriptions after } 6 \text { months of the intervention }\end{array}$ & & & $\begin{array}{l}-33.5 \%(- \\
26.1 \% \text { to }- \\
40.9 \%)\end{array}$ & NR \\
\hline & After 12 months of the intervention & & & $\begin{array}{l}-42.2 \%(- \\
34.2 \% \text { to }- \\
50.2 \%)\end{array}$ & NR \\
\hline & After 24 months of the intervention & & & $\begin{array}{l}-55.5 \%(- \\
45.9 \% \text { to }- \\
65.1 \%)\end{array}$ & NR \\
\hline \multirow{2}{*}{$\begin{array}{l}\text { Hürlimann et al. } \\
2014 \text { [17] }\end{array}$} & The percentage of prescriptions of penicillins for all treated RTls & $11.8 \%$ & $0.7 \%$ & $11.1 \%$ & 0.01 \\
\hline & $\begin{array}{l}\text { the percentage of trimethoprim/ sulfamethoxazole prescriptions for } \\
\text { all uncomplicated lower UTIs treated with antibiotics }\end{array}$ & $13.3 \%$ & $2.7 \%$ & $10.6 \%$ & 0.01 \\
\hline \multirow[t]{3}{*}{$\begin{array}{l}\text { Lemiengre et al. } \\
2018 \text { [16] }\end{array}$} & $\begin{array}{l}\text { Change in immediate antibiotic prescribing (intervention group of } \\
\text { POC CRP vs. control) }\end{array}$ & & & $\begin{array}{l}1.01(0.57 \text { to } \\
1.79)\end{array}$ & $<0.1$ \\
\hline & $\begin{array}{l}\text { Change in immediate antibiotic prescribing (intervention group of } \\
\text { BISNA vs. control) }\end{array}$ & & & $\begin{array}{l}2.04(1.19 \text { to } \\
3.50) \text {. }\end{array}$ & $<0.1$ \\
\hline & $\begin{array}{l}\text { Change in immediate antibiotic prescribing (intervention group } \\
\text { both POC CRP and BISNA vs. control) }\end{array}$ & & & $\begin{array}{l}1.17(0.66 \text { to } \\
2.09)\end{array}$ & $<0.1$ \\
\hline \multicolumn{6}{|c|}{ Audit and feedback interventions } \\
\hline \multirow[t]{2}{*}{$\begin{array}{l}\text { Altiner et al. } 2007 \\
\text { [18] }\end{array}$} & $\begin{array}{l}\text { the ORs for the prescription of an antibiotic (after } 6 \text { weeks of the } \\
\text { intervention) }\end{array}$ & $\begin{array}{l}0.58(0.43 \text { to } \\
0.78), p<0.001\end{array}$ & $\begin{array}{l}1.52(1.19 \text { to } \\
1.95), p=0.001\end{array}$ & & \\
\hline & $\begin{array}{l}\text { the ORs for the prescription of an antibiotic (after } 12 \text { months of the } \\
\text { intervention) }\end{array}$ & $\begin{array}{l}0.72(0.54 \text { to } \\
0.97), p=0.028\end{array}$ & $\begin{array}{l}1.31(1.01 \text { to } \\
1.71), p=0.044\end{array}$ & & \\
\hline $\begin{array}{l}\text { Welschen et al. } \\
2004 \text { [20] }\end{array}$ & $\begin{array}{l}\text { Antibiotic prescription rates for acute symptoms of the respiratory } \\
\text { tract }\end{array}$ & $-4 \%$ & $8 \%$ & $-12 \%$ & $<0.05$ \\
\hline $\begin{array}{l}\text { Gerber et al. } 2013 \\
\text { [19] }\end{array}$ & Rates of broad-spectrum antibiotic prescribing for bacterial ARTIs & $-13 \%$ & $-6 \%$ & $-7 \%$ & $=0.1$ \\
\hline \multirow[t]{2}{*}{$\begin{array}{l}\text { van der Velden } \\
\text { et al. } 2016[21]\end{array}$} & changes in dispensed antibiotics/1000 registered patients (first year) & $-7.6 \%$ & $-0.4 \%$ & $-7.2 \%$ & 0.002 \\
\hline & $\begin{array}{l}\text { changes in dispensed antibiotics/1000 registered patients (second } \\
\text { year) }\end{array}$ & $-4.3 \%$ & $2 \%$ & $-6.3 \%$ & 0.015 \\
\hline \multicolumn{6}{|c|}{ Health policy change strategies } \\
\hline \multirow[t]{3}{*}{ Xiaoxia 2017 [24] } & changes in types of antibiotics & & & & $<0.01$ \\
\hline & changes in drug administration of antibiotics & & & & \\
\hline & changes in combined application of antibiotic & & & & \\
\hline \multirow{2}{*}{$\begin{array}{l}\text { Yip et al. } 2014 \\
\text { [23] }\end{array}$} & Change in antibiotic prescription rates at township health centers & $: 6.6 \%$ & $8.4 \%$ & $-15 \%$ & $<0.05$ \\
\hline & Change in antibiotic prescription rates at village posts & $-6.0 \%$ & $10 \%$ & $-16 \%$ & $<0.05$ \\
\hline \multirow[t]{2}{*}{ Yang 2014 [22] } & $\begin{array}{l}\text { Percentage of prescriptions requiring antibiotics for upper } \\
\text { respiratory tract infections; }\end{array}$ & $-3.02 \%$ & $-0.54 \%$ & $-2.48 \%$ & 0.419 \\
\hline & Percentage of prescriptions requiring two or more antibiotics & $1.93 \%$ & $5.65 \%$ & $-3.72 \%$ & $=$ \\
\hline
\end{tabular}


Table 2 Antibiotic prescribing changes among these included studies (Continued)

\begin{tabular}{|c|c|c|c|c|c|}
\hline First author, year & Primary outcome(s) & $\begin{array}{l}\text { Change in } \\
\text { intervention } \\
\text { group }\end{array}$ & $\begin{array}{l}\text { Change in } \\
\text { control } \\
\text { group }\end{array}$ & $\begin{array}{l}\text { Effect size } \\
(95 \% \mathrm{Cl})\end{array}$ & $\begin{array}{l}P \\
\text { value }\end{array}$ \\
\hline & & & & & 0.049 \\
\hline \multicolumn{6}{|c|}{ Information system supported interventions } \\
\hline \multirow[t]{2}{*}{$\begin{array}{l}\text { Gulliford et al. } \\
2014 \text { [25] }\end{array}$} & Proportion of consultations with antibiotics prescribed & & & $\begin{array}{l}-1.85 \%(0.1 \% \\
\text { to } 3.59 \%)\end{array}$ & $=0.38$ \\
\hline & the rate of antibiotic prescribing for respiratory tract infections & & & $\begin{array}{l}-9.69 \%(0.75 \% \\
\text { to } 18.63 \%)\end{array}$ & $=0.34$ \\
\hline \multirow[t]{2}{*}{$\begin{array}{l}\text { Vellinga et al. } \\
2016 \text { [26] }\end{array}$} & $\begin{array}{l}\text { proportion of antimicrobial prescribing according to guidelines for } \\
\text { urinary tract infection (arm A vs. control) }\end{array}$ & $22.8 \%$ & $-1.70 \%$ & $24.5 \%$ & $<001$ \\
\hline & $\begin{array}{l}\text { proportion of antimicrobial prescribing according to guidelines for } \\
\text { urinary tract infection (arm B vs. control) }\end{array}$ & $16.7 \%$ & $-1.70 \%$ & $18.4 \%$ & $<001$ \\
\hline Blair 2017 [28] & Antibiotic prescribing rates for children's RTIs & $-12 \%$ & $-21 \%$ & $9 \%$ & $=0.018$ \\
\hline $\begin{array}{l}\text { Mainous et al. } \\
2013[27]\end{array}$ & Prescribing of broad-spectrum antibiotics rate & $-16.60 \%$ & $1.10 \%$ & $-17.70 \%$ & $<.0001$ \\
\hline \multirow[t]{3}{*}{$\begin{array}{l}\text { Meeker et al. } 2016 \\
\text { [29] }\end{array}$} & $\begin{array}{l}\text { The antibiotic prescribing rate for antibiotic-inappropriate acute re- } \\
\text { spiratory tract infection (intervention1 vs. control) }\end{array}$ & $-16 \%$ & $-11 \%$ & $-5 \%$ & $<0.01$ \\
\hline & $\begin{array}{l}\text { The antibiotic prescribing rate for antibiotic-inappropriate acute re- } \\
\text { spiratory tract infection (intervention } 2 \text { vs. control) }\end{array}$ & $-18.1 \%$ & $-11 \%$ & $-7.1 \%$ & $<0.01$ \\
\hline & $\begin{array}{l}\text { The antibiotic prescribing rate for antibiotic-inappropriate acute re- } \\
\text { spiratory tract infection (intervention3 vs. control) }\end{array}$ & $-16.3 \%$ & $-11 \%$ & $-5.3 \%$ & $<0.01$ \\
\hline
\end{tabular}

was a highly significant and sustained decrease in 4 antimicrobials prescribing, by $33.5 \%$ (95\% CI -26.1 to -40.9 ), $42.2 \%(95 \% \mathrm{CI}-34.2$ to -50.2$)$ and $55.5 \%$ (95\% CI -45.9 to -65.1$)$ respectively ( $P$ value was not reported). Three RCT studies were done in China, Belgium and Switzerland. The Chinese study had an intervention effect of $-29 \%$ (95\% CI -42 to $-16 ; p=0.0002)$, on antibiotics prescribing rate between the intervention group and the control group [14]. The Swiss study recommended to increase? the use of antibiotics (penicillins) for RTIs and UTIs with an effect of $11.1 \%(P=0.01)$ [17].A UK study found that point-of-care $\mathrm{C}$-reactive protein test without guidance is not an effective strategy to reduce antibiotics prescribing (AOR:1.01(0.57 to 1.79)P<0.1) [16]. A before and after quality assurance study in Spain [13] show that the full intervention and partial intervention group both received the educational interventions according to RTI guidelines, however the full intervention group has an educational workshop on rapid tests. The study shows that the full intervention group had a lower odds ratio of antibiotics prescribing of 0.50 (95\% CI: 0.44-0.57, $p<$ $0.001)$ compared to partial intervention group 0.99 (95\% CI: 0.89-1.10).

\section{Audit and feedback interventions}

Audit and feedback refer to a summary of health workers' performance over specified period of time. This feedbacl is given to them in a written electronic or verbal format, including also in the form of peer review interventions. Four studies evaluated the effects of audit and feedback in primary healthcare providers. All these studies were RCTs. It was noted that all audit and feedback interventions had a positive effect in promoting rationale antibiotics prescribing.

A cluster-RCT study in Germany [18] enrolled 104 general practitioners (GPs) to receive an intervention. This intervention was visit by peers and it was focused on the communication related to antibiotics prescribing?. After the intervention, it was observed that the absolute reduction in prescribing of antibiotics was $11.7 \%(P<0.001)$ and $9.8 \%$ $(P=0.001)$ after 6 weeks and 12 months of the intervention. Jeffrey S. Gerber also evaluated the effect of audit and feedback interventions among primary health care pediatricians on the use of broad-spectrum antibiotics prescribing [19]. They observed that broad-spectrum antibiotics prescribing in pediatric primary health care practices decreased from 26.8 to $14.3 \%$ among intervention group. This is when compared with the control from 28.4 to $22.6 \%(P=0.1)$.

A study in Netherlands reported that the prescription rates for acute symptoms of the respiratory tract in the intervention group fell from 27 to $23 \%$, whereas the control group rose from 29 to $37 \%(P<0.05)$ [20]. Another study in Netherlands aimed to improve antibiotics prescribing quality by audit/feedback intervention. This was embedded in the primary health care practice [21]. The significant differences were observed between intervention and control practices in the changes in dispensed antibiotics/1000 registered patients (first year: 27.6\% 
versus $20.4 \%, P=0.002$; second year: $24.3 \%$ versus $+2 \%$, $P=0.015)$,

\section{Health policy change strategies}

Three policy change interventions were implemented in Chinese rural areas, two of which are matched-pair cluster-randomized trials and one was before and after study. All health policy change interventions had a positive effect in promoting antibiotics prescribing behaviors.

One policy intervention in Ningxia province changed New Cooperative Medical Scheme (NCMS) payments from fee-for-service to a capitated budget with pay-forperformance at township health centers and village posts [23]. And results suggested that capitation with pay-forperformance led to a reduction in approximately $15 \%$ in antibiotics prescriptions $(P<0.05)$.

Another matched-pair cluster-randomized trial was undertaken in Hubei province [22]. They PR (public reported) indicators about physicians' antibiotics prescribing like percentage of prescriptions requiring antibiotics. This intervention resulted in a 9 percentage $(95 \% \mathrm{CI}-17$ to $1 \%$ ) reduction in the use of oral antibiotics (adjusted $R R=$ $39 \%, P=0.027$ ).

Another study was done in Zhejiang province, China, and it was a control before and after study [24]. They took the antibiotic prescribing as an important indicator of physicians' professional promotion and bonus performance. They found that the outcomes of combined application of antibiotics decreased by $9.89 \%(P<0.05)$ and the use of antibiotics for injection reduced to $11.42 \%(P<0.05)$ at primary health care outpatient.

\section{Information system supported interventions}

out of 5 information supported interventions studies, in 3 studies it was observed that had a positive effect on promoting antibiotics prescribing behavior in primary health care providers.

A study including 603,409 patients [25] evaluated the effectiveness of electronically delivered decision support tools at reducing antibiotics prescribing for RTIs, and reported a reduction in antibiotics prescribing 1.85\% (95\% CI, $0.10-3.59 \%, P=0.38$ ). A quasi experimental design [27] study with nine intervention practices and 61 control practices in the Practice Partner Research Network used CDSS (clinical decision support system) intervention. A CDSS embedded in an EHR(electronic health record)resulted in a substantial decrease of $17.7 \%(P<0.0001)$ on changing the overall prescribing of broad-spectrum antibiotics (e.g. macrolide antibiotics) among pediatric and adult patients. The study used suggested alternatives and accountable justification based on EHR [29], and peer comparison interventions. They reported that accountability and peer comparison as behavioral interventions resulted in reducing inappropriate antibiotics prescribing for RTIs.
The antibiotics prescribing rates for antibioticsinappropriate acute respiratory tract infection decreased 5 , 7.1 and $5.3 \%$ respectively in intervention 1,2 and 3 group $(P<0.01)$ as compared to control group.

A cluster-RCT of 30 practices in Irish general practices integrated a reminder in their patient management software [26]. As a result an increase was observed in antimicrobial prescribing for urinary tract infections in the intervention arm (arm A increased 24.5\%, $P<0.001$ and arm B increased $18.4 \%, P<0.001)$ relative to control arm [26]. Another cluster randomized controlled trial in England [28] used a webbased clinician-focused clinical rule to reduce antibiotics prescribing for children. The author reported that the prescribing rates among intervention arm decreased $12 \%$ as compared to control group $21 \%(P=0.018)$.

\section{Discussion}

\section{Main findings of this study}

Most studies had a low or medium quality, indicating to have better quality design. This review found evidence that interventions of educational, audit and feedback, policy change interventions and information system reminders could promote the rational use of antibiotics in primary healthcare settings. It was observed that only three studies did not report a reduction in antibiotics prescribing rates. Educational interventions could achieve significant reductions in antibiotics prescribing by combining with other strategies including financial incentives or providing rapid $\mathrm{C}$-reactive protein tests. The policy change interventions were more common in in low and middle income countries including China, and it was found that these interventions have a good impact on decreasing the antibiotics prescribing rate. The information system supported intervention could have different outcome in different settings. However, we cannot make general recommendations to guide the selection of different interventions due to limitations in heterogeneity of the interventions.

\section{Findings in relation to other research}

In a systematic review conducted at England of antimicrobial Stewardship in Outpatient Settings, it was observed that antimicrobial stewardship programs in outpatient settings improve antimicrobial prescribing without adversely effecting patient outcomes and [31]. These results were in line with our study indicating that primary healthcare providers' prescription behavior interventions are associated with a reductions in antibiotics prescribing and in promoting the rational use of antibiotics. They evaluated the effectiveness of physician-targeted interventions to improve antibiotics use for respiratory tract infections, and reported a reduction of $11.6 \%$ of antibiotics prescription [32]. Another review shows that just developing guidelines is not enough to restrict antibiotics prescribing and there is a need have educational material supplemented to with 
another intervention? [24]. This review found that multiple interventions aiming to improve educational material for the physician' were most often effective [33]. For the audit and feedback interventions, our study finds this strategy is effective in promoting the antibiotics prescribing. This is also consistent with the study done by Davey $\mathrm{P}[5]$.

A previous systematic review has shown that computer interventions, educational sessions, collaboratively developed guidelines and training videos were effective in changing practice of pediatricians. It was also observed that multifaceted and computer interventions work best [34]. The interventions in primary health care were different from the interventions? conducted in the hospital setting. Interventions in hospitals were more systematic such as the introduction of new diagnostic tests to guide antibiotic treatment and expert audit of prescriptions and either feedback provided to prescribers on their prescribing. Primary health care providers' interventions in outpatient usually aim to change individual prescriber's behavior. This behavior is influenced by social norms, attitudes and beliefs [35].

\section{Recommendations for future research}

Future research should focus on the design and methodology of high-quality RCTs. We found that there were few studies reporting the sustainable effects of the interventions [36]. In our opinion the studies should aim for longer periods of follow-up. Future studies assessing the quality of intervention and implementation are needed. Also the interventions should pay more attention towards the providers' behaviors [37].

\section{Strengths and limitations}

This review is vital as we evaluated the effect of primary health care providers targeted interventions and provided an evidence-base. There are many reviews on the effectiveness of antibiotics stewardship of inpatients, however, few focus on outpatients. A key strength of our review is that only studies with a control group, ITS or control before and after studies were included and therefore are more likely to represent the change.

However, there are several limitations in our review. First, we only identified studies that were published, so the results may be affected by publication bias although not all interventions were statistically significant. The effect sizes from the included studies in this review may be misleading because published trials are more likely to demonstrate positive and large intervention effects. Second, most studies identified were from the US, Europe and China which may be suggestive of the bias, however this is what is available in the literature. Third, study designs of included studies were complex and heterogeneous, making it challenging to judge the quality of these studies.

\section{Conclusions}

Our review demonstrated that there were few studies describing antibiotics improving interventions targeted towards primary healthcare providers in LIMCs. It was challenging to compare these studies because the included studies had heterogeneous study designs and were conducted in different settings. There moderate-strength evidence shows that provider-targeted interventions can decrease the antibiotics prescribing and can promote the rational use of antibiotics. Most of the interventions had a moderate or strong effect of antibiotics prescribing reduction or promotion of antibiotics rational use.

\section{Supplementary information}

Supplementary information accompanies this paper at https://doi.org/10. 1186/s41256-020-00171-2.

\section{Additional file 1.}

\section{Abbreviations}

LMICs: Low-income and-Middle-Income Countries; ABR: Antibiotics Resistance; CNKI: China National Knowledge Infrastructure; PICOS: Population, Intervention, Comparison, Outcome and Study design; WHO: World Health Organization; EPOC: Effective Practice and Organisation of Care;

RCTs: Randomized Controlled Trials; ITS: Interrupted Times Series; NRT: NonRandomized Trial; RTIs: Respiratory Tract Infections; URTIs: Upper Respiratory Tract Infections; GPs: General Practitioners; NCMS: New Cooperative Medical Scheme; PR: Public Reported; CDSS: Clinical Decision Support System; EHR: Electronic Health Record

\section{Acknowledgements}

The authors thank Tingting Zhang, the PHD from York University, for her comments and reviews of this manuscript. Many thanks to professor Liying Jia, from Shandong university for her comments and reviews of this manuscript.

\section{Transparency declarations}

None to declare.

\section{Authors' contributions}

YL designed the study, screened the paper, extracted and analysed data, wrote the manuscript and approved the final manuscript as submitted. JY wrote the manuscript, interpreted the data and approved the final manuscript. TZ reviewed the revised manuscript and approved the final manuscript as submitted. RT screened the paper, extracted the data and approved the final manuscript. DY designed the study, reviewed the revised manuscript and approved the final manuscript as submitted.LS designed the study, reviewed the revised manuscript and approved the final manuscript as submitted. SW screened the paper, extracted the data and approved the final manuscript. QS designed the study, reviewed the revised the manuscript and approved the final manuscript as submitted.

\section{Funding}

Qiang Sun is supported by grants from National Natural Science Foundation of China (71774103).

Availability of data and materials

Lu Yao and Qiang Sun had full access to all the data in the study and take responsibility for the integrity of the data and the accuracy of the data analysis. Data will be provided under request to the first authors. 


\section{Ethics approval and consent to participate}

Not applicable.

\section{Consent for publication}

All the authors give their authorization to publish the article.

\section{Competing interests}

The authors declare that they have no competing interests.

\section{Author details}

${ }^{1}$ Centre for Health Management and Policy Research, School of Public Health, Cheeloo College of Medicine, Shandong University, Jinan 250012, China. ${ }^{2} \mathrm{NHC}$ Key Lab of Health Economics and Policy Research (Shandong University), Jinan 250012, China. ${ }^{3}$ Cangzhou Central Hospital, Cangzhou 061001, Hebei, China.

Received: 13 May 2020 Accepted: 8 September 2020

Published online: 17 October 2020

\section{References}

1. Laxminarayan R, Duse A, Wattal C, et al. Antibiotics resistance-the need for global solutions. Lancet Infect Dis. 2013;13(12):1057-98.

2. Jasovsky D, Littmann J, Zorzet A, Cars O. Antimicrobial resistance-a threat to the world's sustainable development. Ups J Med Sci. 2016;121(3):159-64.

3. World Health Organization. Emerging and other communicable diseases: antimicrobial resistance-report by the director-general. Genova: WHO; 1998.

4. World Health Organization. Antimicrobial resistance monitoring: update of activities 1997/1998. Genova: WHO; 1998.

5. Costelloe C, Metcalfe C, Lovering A, et al. Effect of antibiotics prescribing in primary health care on antimicrobial resistance in individual patients: systematic review and meta-analysis. BMJ. 2010;340:c2096.

6. Davey P, Marwick CA, Scott CL, et al. Interventions to improve antibiotics prescribing practices for hospital inpatients. Cochrane Database Syst Rev. 2017;2:Cd003543.

7. Laxminarayan $\mathrm{R}$, Matsoso P, Pant $\mathrm{S}$, et al. Access to effective antimicrobials: a worldwide challenge. Lancet. 2016;387(10014):168-75.

8. Van Dijck C, Vlieghe E, Cox JA. Antibiotics stewardship interventions in hospitals in low-and middle-income countries: a systematic review. Bull World Health Organ. 2018;96(4):266-80.

9. Cross EL, Tolfree R, Kipping R. Systematic review of public-targeted communication interventions to improve antibiotics use. J Antimicrob Chemother. 2017;72(4):975-87.

10. Arnold SR, Straus SE. Interventions to improve antibiotics prescribing practices in ambulatory care. Cochrane Database Syst Rev. 2005;4:CD003539.

11. Effective practice and organisation of care (EPOC). EPOC Taxonomy; 2015. https://epoc.cochrane.org/epoc-taxonomy.

12. Green S, Higgins J. Preparing a cochrane review. Cochrane handbook for systematic reviews of interventions: The Cochrane Collaboration, 2011

13. Llor C, Cots JM, Hernandez S, et al. Effectiveness of two types of intervention on antibiotics prescribing in respiratory tract infections in primary health care in Spain. Happy audit study. Aten Primaria. 2014;46(9):492-500.

14. Wei X, Zhang Z, Walley JD, et al. Effect of a training and educational intervention for physicians and caregivers on antibiotics prescribing for upper respiratory tract infections in children at primary health care facilities in rural China: a clusterrandomised controlled trial. Lancet Glob Health. 2017:5(12):e1258-67.

15. Hernandez-Santiago V, Marwick CA, Patton A, Davey PG, Donnan PT, Guthrie B. Time series analysis of the impact of an intervention in Tayside, Scotland to reduce primary health care broad-spectrum antimicrobial use. J Antimicrob Chemother. 2015:70(8):2397-404.

16. Lemiengre MB, Verbakel JY, Colman R, et al. Reducing inappropriate antibiotics prescribing for children in primary health care: a cluster randomised controlled trial of two interventions. Br J Gen Pract. 2018;68(668):e204-e10. https://doi. org/10.3399/bjgp18X695033 [published Online First: Epub Date].

17. Hurlimann D, Limacher A, Schabel M, Zanetti G, Berger C, Muhlemann K, Kronenberg A. Improvement of antibiotics prescription in outpatient care: a cluster-randomized intervention study using a sentinel surveillance network of physicians. J Antimicrob Chemother. 2015;70(2):602-8.

18. Altiner A, Brockmann S, Sielk M, Wilm S, Wegscheider K, Abholz HH. Reducing antibiotics prescriptions for acute cough by motivating GPs to change their attitudes to communication and empowering patients: a cluster-randomized intervention study. J Antimicrob Chemother. 2007;60(3):638-44.
19. Gerber JS, Prasad PA, Fiks AG, et al. Effect of an outpatient antimicrobial stewardship intervention on broad-spectrum antibiotics prescribing by primary health care pediatricians: a randomized trial. JAMA. 2013;309(22):2345-52.

20. Welschen I, Kuyvenhoven MM, Hoes AW, et al. Effectiveness of a multiple intervention to reduce antibiotics prescribing for respiratory tract symptoms in primary health care: randomised controlled trial. BMJ. 2004;329(7463):431.

21. van der Velden AW, Kuyvenhoven MM, Verheij TJ. Improving antibiotics prescribing quality by an intervention embedded in the primary health care practice accreditation: the ART14 randomized trial. J Antimicrob Chemother. 2016;71(1):25763. https:/doi.org/10.1093/jac/dkv328 [published Online First: Epub Date].

22. Yang L. Public reporting improves antibiotics prescribing for upper respiratory tract infections in primary health care: a matched-pair clusterrandomized trial in China. Health Res Policy Syst. 2014;12(1):9.

23. Yip W, Powell-Jackson T, Chen W, et al. Capitation combined with pay-forperformance improves antibiotics prescribing practices in rural China. Health Aff. 2014;33(3):502-10

24. Xiaoxia L. Rationality analysis of antibioticss prescription in 17 primary health institutions and emergency department in jiande district: before and after intervention. Chin Hosp Drug Eval Anal. 2017;17(4):534-6.

25. Gulliford MC, van Staa T, Dregan A, McDermott L, McCann G, Ashworth M, Charlton J, Little P, Moore MV, Yardley L. Electronic health records for intervention research: a cluster randomized trial to reduce antibiotics prescribing in primary health care (eCRT study). Ann Fam Med. 2014;12(4):344-51.

26. Vellinga A, Galvin S, Duane $\mathrm{S}$, et al. Intervention to improve the quality of antimicrobial prescribing for urinary tract infection: a cluster randomized trial. Can Med Assoc J. 2016;188(2):108-15.

27. Mainous AG, Lambourne CA, Nietert PJ. Impact of a clinical decision support system on antibiotics prescribing for acute respiratory infections in primary health care: quasi-experimental trial. J Am Med Inform Assoc. 2013;20(2):317-24.

28. Blair PS. Feasibility cluster randomised controlled trial of a withinconsultation intervention to reduce antibiotics prescribing for children presenting to primary health care with acute respiratory tract infection and cough. BMJ Open. 2017;7(e014506):1-11.

29. Meeker D, Linder JA, Fox CR, et al. Effect of behavioral interventions on inappropriate antibiotics prescribing among primary health care practices: a randomized clinical trial. JAMA. 2016;315(6):562-70. https://doi.org/10.1001/ jama.2016.0275 [published Online First: Epub Date].

30. Suggested risk of bias criteria for EPOC reviews [internet]. London: Cochrane; 2017. Available from: http://epoc.cochrane.org/epoc-specificresources-review-authors.

31. Drekonja DM, Filice GA, Greer N, et al. Antimicrobial stewardship in outpatient settings: a systematic review. Infect Control Hosp Epidemiol. 2015;36(2):142-52.

32. van der Velden AW, Pijpers EJ, Kuyvenhoven MM, Tonkin-Crine SK, Little P, Verheij TJ. Effectiveness of physician-targeted interventions to improve antibiotics use for respiratory tract infections. Br J Gen Pract. 2012;62(605):e801-7.

33. Vodicka TA, Thompson M, Lucas P, et al. Reducing antibiotics prescribing for children with respiratory tract infections in primary health care: a systematic review. Br J Gen Pract. 2013;63(612):e445-54.

34. Boonacker CW, Hoes AW, Dikhoff MJ, et al. Interventions in health care professionals to improve treatment in children with upper respiratory tract infections. Int J Pediatr Otorhinolaryngol. 2010;74(10):1113-21.

35. Charani E, Edwards R, Sevdalis N, et al. Behavior change strategies to influence antimicrobial prescribing in acute care: a systematic review. Clin Infect Dis. 2011;53(7):651-62.

36. Tonkin-Crine SK, Tan PS, van Hecke O, Wang K, Roberts NW, McCullough A, et al. Clinician-targeted interventions to influence antibiotics prescribing behaviour for acute respiratory infections in primary health care: an overview of systematic reviews. Cochrane Database Syst Rev. 2017;9:CD012252.

37. Rogers Van Katwyk S, Grimshaw JM, Nkangu M, Nagi R, Mendelson M, Taljaard $M$, et al. Government policy interventions to reduce human antimicrobial use: a systematic review and evidence map. PLoS Med. 2019;16(6):e1002819. 